iodoform gauze 1 yard long and 1 yard wide, rolled loosely (not tightly) on itself, with all selvages turned in, is then carried into the pelvis, one end of which is made to enter the opening previously made through the posterior vaginal fornix. There should be no set rule, however, as to the dimension of the gauze employed, but a quantity sufficient to fill the pelvis and fairly cover all stumps and raw surfaces should be used. This method will prevent to a large degree oozing from raw surfaces left in breaking up adhesions, and by keeping the intestines and omentum out of the pelvis, it will prevent subsequent union between these structures and the pelvic cavity. There can be no objection to the employment of the preliminary posterior vaginal incision, because it is quickly executed and does not endanger any organ if properly performed. Where a preliminary posterior incision has not been made this operation can be done, but with a greater difficulty from above by picking up the vaginal wall with a double tenaculum close to the cervix, and incising freely. It is, however, much easier and much safer to make the preliminary incision from below. The gauze drain should be allowed to remain, as has been stated, from six to eight days and it should then be removed, preferably under short chloroform anesthesia. No repacking should be resorted to and no douches should be given for several days, because of the danger of washing or flushing fluid into the pelvic cavity through the vaginal opening. Douches should not be used for several days and then only if material is present to require douching. If reaccumulation takes place in the pelvic cavity subsequently to the removal of the gauze, spontaneous opening usually occurs through the line of vaginal incision or, if necessary, the cicatrix can be readily broken through by digital pressure.

1621 Spruce Street.

\section{HISTORY OF A TYPHOID CARRIER}

MAZYCK P, RAVENEL, M.D.

Professor of Bacteriology, University of Wisconsin; Director, Wisconsin State Laboratory of Hygiene

MADISON, WIS.

In the fall of $1910 \mathrm{Mr}$. A. moved from Minnesota to the town of G., Wisconsin, bringing with him his wife and three boys. He bought a farm 4 miles northeast of the village. In December, 1909, Mr. A. had been operated on in St. Paul for pyonephrosis, and a tumor mass weighing 5 pounds removed. No bacteriologic examination was made. One of the doctors who assisted at the operation states that six months before he had treated $\mathrm{Mr}$. A. for typhoid fever. About. the time of moving to Wisconsin the eldest son had typhoid fever, and soon after the two other sons and their mother came down with the disease.

Mr. B. with his family, consisting of his wife, two boys and a girl, moved from Minnesota to Wisconsin about the same time, having purchased a farm in the immediate neighborhood of $\mathrm{Mr}$. A. While the buildings on this place were being put in order Mr. B.'s family stayed at the home of Mr. A., with the apparent result that first the daughter, and soon after Mr. B. and the two sons came down with typhoid fever.

In the fall of 1911 Miss C., a niece of Mr. A., came from St. Paul to teach in the public schools. She was in the habit of spending the week-end at the house of
Mr. A. After six weeks' residence in the town of $G$. she became ill with typhoid fever.

At the same time a sister of Mr. A. visited him and soon after returning to her home suffered from typhoid fever also.

About Aug. 15, 1911, Mr. D. visited at the home of Mr. A. and took supper with him. September 20 Mr. D. entered a hospital after having been sick for some days, and a diagnosis of typhoid fever was made. His illness began during the first week of September.

In the spring of 1912 two young men, $E$. and $F$., who were working at the home of $\mathrm{Mr}$. A., both contracted typhoid fever.

In the fall of the same year Mrs. G., a sister of Mrs. A., accompanied by her son, spent a few weeks at the home of Mr. A. Soon after returning home both contracted typhoid fever.

In the latter part of 1912 or January, 1913, Mr. H., a brother of E., spent a night at the home of Mr. A., and twelve days afterward came down with typhoid fever.

In June, 1913, Miss I., a niece of Mr. A., living near him, suffered from typhoid fever. There had been frequent visiting between the two families.

On or about Oct. 15, 1913, Mr. J. took the Reverend $\mathrm{K}$., his wife and two children to the home of Mr. A. for a visit. They did not take a meal at the house, but the children became hungry and cookies were handed. October 28, the Reverend $K$. bought butter from Mr. A for table use, and on November $2 \mathrm{Mr}$. A. and family dined at the home of the Reverend $K$. On November 11 the two children of the Reverend $K$. became ill with typhoid fever, and on November 30 Mrs. $K$ and her husband also went down with the disease, Mrs. K. dying.

It thus appears that twenty-one cases of typhoid fever occurred among persons in this community, or those who had visited there, and all of them had been in contact for longer or shorter periods of time with Mr. A.

These facts were called to my attention in June, 1913, and the circumstances were so suspicious that I advised doing Widal tests on the family of Mr. A. Mr. A. himself and one son gave positive reactions. We then shipped tubes of bile to the health officer of the town, asking him to inoculate them with the urine and feces from these two persons. Examination of these tubes showed the presence of typhoid bacilli in the urine of Mr. A., but not in the feces. Subsequent examinations have confirmed this finding. Even after treatment with hexamethylenamin for a considerable period of time the typhoid bacillus can still be isolated from the urine of $\mathrm{Mr}$. A. with a considerable degree of regularity.

In the fall of 1913 Dr. Fred Johnson was appointed deputy state health officer, and since that time the field work on this case has been under his charge, and he has collected a number of specimens for examination.

In considering this run of cases of typhoid fever the question may well be asked, With what degree of certainty can the origin of these cases be traced to Mr. A.? In a few of them, as for example Mr. H., who spent a single night at the home of $\mathrm{Mr}$. A., and of Miss I., who had simply visited, the exposure seems to have been very slight, and it is hard to state with any degree of certainty that the disease was contracted from Mr. A. The period of incubation in the case of Mr. H. was unusually short, although not shorter than 
has been noted in a number of cases. In the case of Mr. D. the exposure also seems to have been slight. The exposure of the Reverend $K$. and his family appears to have been sufficient, especially in view of the purchase of butter prepared at the farm, and the period of incubation was such that it is not going far out of the way to connect these cases directly or indirectly with $\mathrm{Mr}$. A.

It must be noted also that all of these patients with the exception of Miss I. are known to have taken food served at the house, and on account of frequent visits it is almost certain that Miss $I$. had also had food there.

Every effort has been made to exclude other sources of infection. The water-supply of the town of $G$. was examined and found to be above suspicion. There was no typhoid fever in this community except among those persons who had been in contact with $\mathrm{Mr}$. A. Admitting that a few of these cases are doubtful, it is nevertheless reasonable to conclude that a great majority of them were infected directly or indirectly from Mr. A.

\section{RATIONALE OF THE USE OF . ANTISEP- TICS AND GERMICIDES IN INFLAM- MATIONS OF THE MUCOUS MEMBRANES *}

MARSH PITZMAN, M.D. ST. LOUIS

This paper concerns itself with the question why antiseptics and germicides influence favorably the infections of the mucous membranes. The simplest answer, the one accepted for several decades almost as gospel, is that antiseptics or germicides gradually kill off the bacteria and so terminate the infection. Of course, one can use or misuse an argument at will so long as the world is with one, but the thinking element of the medical profession has become skeptical. Once the bacteria lie in the depths of the tissues, except as to be noted later, a great mass of honest experimental work has shown that it is impossible to reach them with our antiseptics or germicides as used in practice. This demonstration accounts for the honest skepticism and growing discontent with the old explanation.

The general surgeons are going through a similar evolution. The belief that the use of a moist antiseptic or germicidal dressing over an infected wound has any direct influence on the course of the infection within the tissues is rapidly losing ground. The progressive surgical opinion of to-day is that in infected wounds a moist saline or water dressing will accomplish all that an antiseptic could without the risk of the occasional bad effects of the antiseptic or germicide.

First, I wish to make sure that we are agreed on the use of terms. A germicide is a preparation that kills vegetative bacteria on true contact practically instantaneously. Spores require especially strong germicides to bring about their instant destruction, such as free chlorin, intense heat, etc., and consequently are not considered in this definition. An antiseptic is an agent which hinders the growth of bacteria. After

* Read before the St. Louis Medical Society, April 18, 1914.

* My previous papers on similar topics are: Hyg. Rundschau, 1909, No. 12; Fallacies in the Understanding of Antiseptics and Germicides July 23. 1910. p. 308: Am. Jour. Ophth.. 1912, xxix, 1. hours or days antiseptics of ten kill bacteria, but do not necessarily do so. The German term, entwicklungshemmend-development checking - is much preferable for a clear understanding of the meaning.

\section{PROPHYLACTIC USES}

One most important use of the germicides is a byproduct of medical science of the last decade. I refer to the prophylactic use of germicides on a mucous membrane which has been exposed to infection. Under such circumstances the bacteria are on the surface and theoretically should be killed off by the proper use of a germicide. The strength of solution which should be used to make sure of killing the bacteria, and at the same time do a minimum of injury to the tissues, constitutes an open question for individual experience and judgment. From the points of view, however, of both theory and the literature, I would strongly favor the use of an active germicide and condemn the weaker antiseptics, such as argyrol or collargol, as not being efficient in killing off bacteria. Credé's prophylaxis of ophthalmia neonatorum, I take it, is accepted as being efficient in killing off the gonococcus on the surface and thus preventing the infection. The original 2 per cent. solution is now held to be unnecessarily severe, so that 0.5 per cent. or even weaker solutions have justly come into use.

The prophylactic use of a germicidal injection after exposure to venereal infection from a theoretical point of view is reasonable. Of late this procedure has gained greatly in the number of its adherents. The more recent army reports are favorable to its efficiency in practice. The exact strength of solution opens a field for individual views, though here again weak antiseptics should not be depended on.

Another direct use of germicidal power belongs to the ophthalmologist exclusively on account of the anatomic structure of the cornea. Because of the density of structure and consequent comparatively limited possibilities of blood-and serum-supply, the cornea is comparable to bony tissue. In such tissues the infection tends to remain localized and so theoretically could be blotted out by the use of a germicide r iood authority affirms that it works out in practice.

\section{ACTION IN ACUTE INFLAMMATION}

Now I venture into the dangerous field of comparison. Let us take up the established surgical principles in dealing with an abscess. Once an abscess has reached such a size that fluctuations can readily be made out, practically always the fluid contents must be discharged before it will heal. When neglected, the pus often works its own way out; more properly the knife hastens its escape. The rational explanation of the healing is that the tissues no longer have to struggle against so great a quantity of toxin and consequently are able to overcome the infection. It has been often directly proved, of course, that a fresh abscess contains toxin in quantity. Many abscesses will heal, no matter in what part they are opened; others refuse to heal until opened at the lowest gravity point; hence the established surgical rule. This, I should consider, would rule out the question of tension, for tension is relieved as well by a high as by a lowest-point incision. The pus with its toxin must drain out of the wound entirely in order to promote recovery. But certain abscesses cannot, on account of their anatomic relations, be drained from the lowest point; such, for instance, are deep collections, or 